\title{
Educação do campo e a necessária superação da dualidade rural e urbana
}

Rural education and the necessary overcoming of rural and urban duality

Educación de campo y la necesidad de superar la dualidad rural y urbana

Antônio Cláudio Moreira Costa ${ }^{1}$

RESUMO: Neste texto, busco apresentar alguns elementos para discutirmos a educação do campo na perspectiva de fortalecer a resistência contra a lógica capitalista que, baseada num equivocado entendimento de desenvolvimento, tenta anular as manifestações culturais, políticas, tecnológicas, ambientais e educativas existentes nos territórios camponeses. A motivação deste trabalho parte da constatação de que a educação destinada aos povos do campo, apesar das políticas públicas existentes, continua sendo marginalizada e negligenciada pela maioria dos governos estaduais e municipais. As reflexões desenvolvidas tiveram como aporte metodológico a pesquisa bibliográfica e as análises de experiências desenvolvidas pelo Grupo de Estudos e Pesquisa em Educação, Cultura e Comunicação (GEPECC), da Faculdade de Educação, Universidade Federal de Uberlândia.

Palavras-chave: Educação do campo. Movimentos sociais. Formação de professores. Rural e urbano.

ABSTRACT: In this text, I try to present some elements to discuss rural education in the perspective of strengthening resistance against capitalist logic. Based on a mistaken understanding of development, capitalism tries to cancel the cultural, political, technological, environmental and educational manifestations existing in the peasant territories. Education for rural people, despite existing public policies, continues to be marginalized and neglected by most state and municipal governments. The reflections developed had as methodological support the bibliographic research and the analysis of experiences developed by the Group of Studies and Research in Education, Culture and Communication, Federal Universitu of Uberlândia.

Keywords: Rural education. Social movements. Teachers training. Rural and urban.

RESUMEN: En este texto busco presentar algunos elementos para discutir la educación rural desde la perspectiva de fortalecer la resistencia contra la lógica capitalista que se basa en una comprensión errónea de los intentos de desarrollo para anular las manifestaciones culturales, políticas, tecnológicas, ambientales y educativas que existen en los territorios campesinos. La motivación para este trabajo proviene del hecho de que la educación para los pueblos rurales, a pesar de las políticas públicas existentes, sigue siendo marginada y descuidada por la mayoría de los gobiernos estatales y municipales. Las reflexiones desarrolladas tuvieron como soporte metodológico la investigación bibliográfica y el análisis de experiencias desarrolladas

\footnotetext{
${ }^{1}$ Doutor em Educação pela Universidade Estadual Paulista Júlio de Mesquita Filho, São Paulo, Brasil; professor associado da Faculdade de Educação da Universidade Federal de Uberlândia, Minas Gerais, Brasil; líder do Grupo de Estudos e Pesquisas em Educação, Cultura e Comunicação (GEPECC/FACED/UFU) (acmoreira@ufu.br).
} 
por el Grupo de Estudios e Investigación en Educación, Cultura y Comunicación (GEPECC), Universidad Federal de Uberlandia.

Palabras clave: Educación rural. Movimientos sociales. Formación del profesorado. Rural y urbano.

\section{INTRODUÇÃO}

O contexto político mundial é marcado pela insegurança e criminalização dos movimentos sociais, e de todos aqueles que almejam uma sociedade mais justa. Em todos os continentes temos observado a ascensão de ideias fascistas exacerbando o preconceito, o racismo, intolerâncias de todas as ordens, levando muitos países ao caos. Na América Latina, a ofensiva neoliberal e a articulação de uma ultradireita reacionária aprofundam os problemas sociais, penalizando severamente a classe trabalhadora por meio de reformas que retiram direitos historicamente conquistados e reduzem as responsabilidades do estado com a promoção do bem estar social. Brasil, Bolívia, Chile e Venezuela são boas referências para ilustrar esse contexto.

No Brasil, o discurso de ódio despertado pelo atual (des)governo brasileiro contra os movimentos socias de luta pela terra (Sem Terras, Negros e Povos Indígenas) vai ao encontro dos interesses da bancada ruralista e de grupos multinacionais que desejam apropriar-se do território nacional com um único objetivo: exploração das riquezas naturais. Preservação territorial, ambiental, da biodiversidade, enfim da vida em todas as suas manifestações, é uma bandeira que deve ser levantada por todos.

Para tanto, faz-se necessária a criação de espaços coletivos de discussão, com vistas à articulação da resistência da classe trabalhadora e a construção de alternativas contra hegemônicas para os povos do campo e da cidade, afinal de contas esses espaços com suas diferenças não deixam de ser complementares. A Jornada Universitária da Reforma Agrária (JURA), é uma dessas alternativas, organizada a partir da articulação entre movimentos sociais e professores universitários, na perspectiva de dar maior visibilidade à questão agrária no Brasil. 


\section{A pseudo urbanização do território}

A partir do último quarto do século XX passa a ser disseminada a ideia de que o Brasil vai se "modernizando" (o que não é de todo errado) e que, nesse processo, vai assumindo uma caracterização mais urbana. As ideias urbanocêntricas ganham força nos discursos oficiais, sobretudo a partir do regime tecnoburocrata dos militares, e passam a compor o imaginário da população, que por questões ideológicas impostas pelo capitalismo, têm restrições em assumir a identidade camponesa, uma vez que ideologicamente foi convencionado afirmar que, via de regra, o rural está marcadamente identificado com o atraso.

A construção ideológica da urbanização está atrelada aos interesses do capital na desterritorização dos espaços ocupados pelos sujeitos do campo, com vistas a uma reterritorização pautada na lógica produtiva imperialista neoliberal. Estamos imersos em um processo de urbanização globalizante, em que, no Brasil, nos anos 2000, os "dados oficiais" apontam que $81,2 \%$ da população é urbana. Tais dados, segundo Veiga (2001), foram coletados de forma distorcida e apresentam o Brasil como sendo um país essencialmente urbano, fato que serve para desvirtuar a análise do desenvolvimento urbano/rural e desviar o foco das políticas públicas.

Para o professor Veiga (2001), essa maneira equivocada de conceber o urbano é um dos maiores entraves ao desenvolvimento da sociedade brasileira. Para ele, "o chamado 'grau de urbanização' corresponde à porcentagem das pessoas que residem em sedes de municípios e de distritos, independentemente de qualquer consideração sobre suas características geográficas", como por exemplo, a densidade demográfica, um dos principais indicadores das concentrações populacionais próprias às cidades, que as distingue dos níveis de rarefação que caracterizam o campo.

Na perspectiva metodológica proposta por Veiga (2001), se considerarmos como critérios de ruralidade a localização dos municípios, o tamanho da sua população e a sua densidade demográfica, apenas 411 dos 5.507 municípios brasileiros existentes em 2000 seriam considerados urbanos.

Ainda de acordo com o autor, em $70 \%$ dos municípios brasileiros as densidades demográficas são inferiores a $40 \mathrm{hab} / \mathrm{km}^{2}$, enquanto o parâmetro da OCDE (Organização de Cooperação e de Desenvolvimento Econômico) para que uma localidade seja considerada urbana é de 150 
hab/ $/ \mathrm{km}^{2}$. Levando-se em consideração os critérios da OCDE adotados por Veiga (2002), é possível inferir que $80 \%$ dos municípios brasileiros (4.485), onde reside $30 \%$ da população brasileira, são rurais e que, portanto, suas sedes municipais são apenas cidades imaginárias.

Tendo como referência esses dados Veiga (2001, p. 101) adverte que eles

trazem duas constatações que não deveriam ser tão ignoradas no debate público sobre o desenvolvimento da sociedade brasileira. Em primeiro lugar, que é pura ilusão encarar a população rural como uma minoria condenada à extinção por volta de 2030, como sugere a projeção do disparate estadonovista sobre o "grau de urbanização". Em segundo, que a cadência da migração rural/urbana da última década impede que se fale genericamente do "êxodo rural".

De acordo com Veiga (2001), há consenso entre os economistas de que a distribuição espacial da população deve ser compreendida a partir do rearranjo espacial das atividades econômicas. Mas isso não basta para transcender a concepção equivocada sobre o desenvolvimento imposto à sociedade brasileira. Faz-se necessário compreender que, no campo, as atividades do setor primário são preponderantes, mas também existem atividades dos setores secundário e terciário. A respeito disso, Wanderley (1988 apud GERARDI; SALAMONI, 2014, p. 173) corrobora, ao afirmar que:

A economia camponesa não representa "algo" residual, necessariamente atrasado e com tendências à extinção diante do desenvolvimento do capitalismo. Ao contrário, o próprio capital cria um esforço para a reprodução da produção familiar, tornando-a não algo diferente do capital, mas um elemento do seu próprio funcionamento.

Portanto, embora no processo produtivo sejam utilizadas tecnologias modernas e a produção esteja interrelacionada aos complexos agroindustriais, os camponeses não perdem sua condição de produtores familiares; logo, o território camponês não pode ser entendido como um espaço urbano, embora seja possível observar nesse espaço, alguns elementos que compõem o território urbano.

Negar a ruralidade brasileira é privar milhares de sujeitos históricos ao exercício pleno da cidadania, é impor-lhes um processo de aculturação referenciado por um complexo de relações significativas à lógica hegemônica capitalista e neocolonialista. A ofensiva contra hegemônica deve ter como princípio o pressuposto de que urbano e rural, apesar das características distintas que os constituem, não podem ser compreendidos de maneira isolada, pois ambos se complementam. Portanto, o desenvolvimento da sociedade brasileira não pode 
ter como fundamentação exclusiva o crescimento econômico a partir de uma pseudo urbanização. Marcuzzo e Ramos (2004, p. 2), corroboram com as ideias esboçadas aqui, ao afirmarem que:

O desenvolvimento deve ser entendido não só como o crescimento econômico, mas também como a melhoria da qualidade de vida da população, bem como a sua sustentabilidade baseada na satisfação das necessidades das gerações presentes, sem comprometer a capacidade das gerações futuras também poderem satisfazer suas necessidades, está atrelado à adoção de estratégias e políticas públicas tanto no meio urbano, quanto no meio rural.

Superar a perspectiva estadonovista sobre a compreensão de desenvolvimento e consequentemente sobre a definição de urbano e rural é uma das condições necessárias para a formulação e implantação de políticas públicas que possam contribuir efetivamente para proporcionar aos sujeitos do campo e das cidades o exercício pleno da cidadania, com qualidade de vida, sustentabilidade e respeito irrestrito a diversidade.

\section{Educação do Campo: um projeto de vida e dignidade alicerçado na cultura popular}

Não vou sair do campo pra poder ir pra escola, educação do campo é direito e não esmola.

(Gilvan Santos, artista popular do MST).

A terminologia Educação do Campo não é apenas uma questão semântica. Expressa, antes de tudo, uma concepção e uma práxis política libertadora na perspectiva freireana. Educação do Campo é um projeto de humanização e de resgate de direitos, gestado nos movimentos sociais do campo, a partir do enfrentamento histórico da lógica capitalista de usurpação do território e do conhecimento. Portanto, educação do campo não surge de uma política do estado brasileiro, mas sim das reivindicações dos movimentos sociais de luta pela terra, em especial, o Movimento dos Trabalhadores Rurais Sem Terra (MST).

No final dos anos de 1980, o MST insere a questão agrária brasileira na agenda política e, mais do que isso, dá visibilidade e voz para sujeitos historicamente marginalizados pelas políticas públicas. Com as ações organizadas de ocupação de territórios dominados ilicitamente pelo capitalismo agrário, e expostos de forma espetacularizada pelo grande aparelho ideológico do estado (as mídias), a luta pela terra no Brasil chega a todos os estados brasileiros e ganha destaque internacional. 
As ações do MST desenvolvidas nos estados do sul e do sudeste foram as que deram maior visibilidade à luta pela terra, pois nessas regiões a concentração fundiária, em decorrência de processos de grilagem e extermínio de populações tradicionais, atingia níveis altíssimos e a burguesia agrária não queria perder seus privilégios. A reação violenta e covarde dos ruralistas não logrou o êxito esperado. Mesmo com muito sangue derramado a luta teve sequência e as intervenções das lideranças foram cada vez mais qualificadas e fundamentadas, levando o MST ser reconhecido como o maior e mais organizado movimento social da América Latina.

No entendimento das lideranças do MST, o Estado brasileiro precisa discutir a questão agrária e não simplesmente a reforma agrária, pois essa é apenas uma parte dela. A questão agrária deve passar necessariamente pela reforma agrária, mas também pela discussão dos recursos imprescindíveis à permanência e produção (linhas de financiamento específicas para habitação, plantio, colheita, comercialização, insumos agrícolas etc.), educação, saúde etc., nas áreas conquistadas.

No processo de luta pela terra organizado pelo MST, a questão da educação e da cultura ganha espaço privilegiado, pois partia-se do pressuposto de que nos espaços conquistados pelos trabalhadores rurais sem terra a escola deveria estar comprometida com a transformação da realidade e a cultura dos povos do campo deveria ser resgatada e mais valorizada com objetivo de construir e fortalecer a identidade camponesa. Sobre essas considerações, Ghedin (2012, p. 27) corrobora conosco ao afirmar que:

Não há identidade, como forma de expressão própria, sem uma intensa luta política para instituir, diante de um sistema hegemônico, uma identidade que particularmente expressa um modo de ser que se distingue dos demais. [...] A identidade é expressão de um poder política que não nos chega senão por meio da luta que se constrói politicamente. [...] Não é possível construir a identidade sem pensar, antes, a cultura e suas formas de expressão.

É possível inferir que, com base nesses pressupostos, o Setor de Educação do MST apresenta os princípios educativos que deveriam orientar os trabalhos nas escolas dos assentamentos e acampamentos da reforma agrária. Paralelamente, a isso, os cantores e poetas ligados organicamente ao movimento produzem uma cultura militante, engajada com a luta social e comprometida com a valorização dos valores camponeses, que anima e impulsiona a militância. A síntese educacional e cultural da qual estamos falando pode ser encontrada no Caderno $\mathrm{n}^{\circ} 8$ do Setor de Educação do MST: A escola que temos e a escola que queremos, e 
nas músicas e poemas dos companheiros Zé Pinto e Gilvan Santos, dentre outros militantes e simpatizantes do Movimento.

Diante da conjuntura política da última década do século XX, as tensões existentes no campo não poderiam mais ser ignoradas pelo governo brasileiro; as vozes dos sujeitos sociais do campo (quilombolas, indígenas, caiçaras, extrativistas, ribeirinhos, sem terras) ecoavam de norte a sul do país, tornando cada vez mais clara a disputa de dois projetos distintos, de um lado, um projeto hegemônico com objetivo de atender as necessidades do capitalismo/imperialismo e de manutenção dos privilégios de uma minoria elitizada; de outro, um projeto contra hegemônico que visa transformar a sociedade numa perspectiva sustentável, solidária e cidadã.

De acordo com Caldart (2004), é em 1997, durante as discussões do I Encontro Nacional de Educadores da Reforma Agrária (ENERA), que o termo "campo" aplicado à educação passa a ser utilizado pelos coletivos de educadores dos movimentos sociais. Segundo Vilhena Júnior e Mourão (2012), buscava-se, nessa fase, um entendimento nacional sobre a educação dos sujeitos do campo. Era consenso entre os participantes do I ENERA, era preciso gestar uma nova metodologia educacional para as escolas rurais; era preciso romper com as referências e práticas das áreas urbanizadas e levar em consideração as especificidades do meio rural, onde o meio ambiente, o trabalho, a cultura e a formação política são indissociáveis. Em outras palavras, estava evidenciado que as escolas inseridas no campo eram desvinculadas da realidade dos sujeitos camponeses e se constituíam quase sempre como um apêndice das escolas urbanas. Portanto, precisariam ser ressignificadas e transformadas em escolas do campo.

As escolas no campo estão ligadas a um projeto educativo do capital, chancelado por organismos internacionais e referendado pela elite empresarial agrária brasileira. Portanto, esse tipo de escola "aniquila a possibilidade de o ser humano se constituir com sujeito de sua história e reduz toda possibilidade de intervenção no mundo apenas a uma forma de manipulação nas disputas pela hegemonia” (GHEDIN, 2012, p. 19). As escolas do campo, em contrapartida, estão ligadas a um projeto emancipador/libertador, gestado na práxis e na dialética das lutas sociais. A educação do campo dá aos educandos subsídios teórico-práticos para exercerem sua condição de sujeitos históricos. "Ser sujeito não é uma dimensão do humano, é uma condição sem a qual não se faz ser humano" (GHEDIN, 2012, p.19). 
É importante notar que as músicas dos cantadores do MST sintetizavam essas discussões e as mensagens nelas contidas eram acessíveis a todos os trabalhadores rurais, independentemente da escolaridade, pois essas músicas partiam de um princípio fundamental da pedagogia freirena: a "leitura do mundo precede a leitura da palavra". Vejamos uma dessas músicas:

\section{Prá soletrar a liberdade}

Tem que estar fora de moda criança fora da escola, pois há tempo não vigora o direito de aprender Criança e adolescente numa educação decente pra um novo jeito de ser

pra soletrar a liberdade na cartilha do $\mathrm{ABC}$. Ter uma escola em cada canto do Brasil com um novo jeito de educar pra ser feliz Tem tanta gente sem direito de estudar

É o que nos mostra a realidade do país. Juntar as forças, segurar de mão em mão, numa corrente em prol da educação desafiando dentro dos assentamentos

Reforma Agrária também na Educação Juntar as forças, segurar de mão em mão, numa corrente em prol da educação Se o aprendizado for além do Be A Bá, todo menino vai poder ser cidadão.

Alternativa pra empregar conhecimento Movimento já mostrou para a nação desafiando dentro dos assentamentos Reforma Agrária também na Educação.

(Zé Pinto)

Entre lutas e poesias, misturando sonhos e utopias, o setor de educação do MST com seus quadros de intelectuais, juntamente com outros movimentos camponeses e acadêmicos identificados com as propostas desses novos sujeitos sociais, foram consolidando as bases da educação do campo. É importante, ressaltarmos que a expressão "do campo" é utilizada para designar um espaço geográfico e social que possui vida em si e necessidades próprias, como “parte do mundo e não aquilo que sobra além das cidades". O campo é concebido enquanto espaço social com vida, identidade cultural própria e práticas compartilhadas, socializadas por aqueles que ali vivem. 
O movimento de educadores comprometidos como os povos do campo rompeu com o paradigma da escola rural (no campo) e reafirmou o paradigma da escola do campo. Em 1998, a partir da I Conferência Nacional por uma Educação Básica do Campo, foi constituído o Movimento Por uma Educação Básica do Campo, representando uma mudança paradigmática, em que se apresentam princípios orientadores de uma educação contra hegemônica que valoriza a cultura e os saberes camponeses, o trabalho como princípio educativo, a formação crítica e política dos educandos e a cooperação em detrimento do individualismo tão explícito na educação rural/tradicional.

A partir da I Conferência e do Movimento Por uma Educação Básica do Campo, o latifúndio do saber passa a ser ocupado e alguns programas específicos para as populações do campo foram conquistados, como, por exemplo, o Programa Nacional de Educação na Reforma Agrária (PRONERA). No entanto, a conquista mais significativa é a aprovação das Diretrizes Operacionais para a Educação Básica nas Escolas do Campo (Resolução no 1, de 3 de abril de 2002/CNE/MEC). Essas diretrizes estabelecem em seu Art. $2^{\circ}, \S$ único, que:

a Educação do campo é uma concepção político-pedagógica voltada para dinamizar a ligação dos seres humanos com a produção das condições de existência social, na relação com a terra e o meio ambiente, incorporando os povos e o espaço da floresta, da pecuária, das minas, da agricultura, os pesqueiros, caiçaras, ribeirinhos e extrativistas. (BRASIL, 2002).

Diante das breves considerações feitas até aqui e do que está exposto no trecho acima das Diretrizes, fica evidenciada que a educação do campo exige: comprometimento político e ético dos profissionais da educação que estão atuando nas escolas do campo e uma transformação radical das práticas educativas até então desenvolvidas; exige que muitos profissionais resgatem sua humanidade; exige a construção do sentimento de pertencimento à escola e à comunidade; exige postura dialógica, crítica e questionadora; exige formação política e ideológica, pois neutralidade é um mito. Nessa perspectiva, faz-se necessário compreender os processos educativos desenvolvidos no campo, na diversidade de dimensões que os constituem como processos sociais, políticos e culturais; formadores do ser humano e da própria sociedade (ARROYO; CALDART; MOLINA, 2004, p. 12-13). 


\section{CONSIDERAÇÕES FINAIS}

Levando-se em consideração os dados demográficos dos municípios que compõem a região do Triângulo Mineiro é possível afirmar que essa é uma região essencialmente rural, mas que quer ser compreendida como uma região urbana. O rural é sempre associado ao atraso, enquanto o urbano representa o desenvolvimento e a oportunidade de maior qualidade de vida. Infelizmente a ideologia urbanoide, ancorada nos ideais burgueses e agronegocistas, consegue iludir a maioria da população do Triângulo Mineiro, que não assume a identidade de camponeses e, portanto, não se interessa pelas demandas daqueles que se assumem como camponeses.

Essa situação impõe aos movimentos desafios a serem superados para a efetivação da educação do campo: ampliar o debate sobre rural e urbano; problematizar as ações do agronegócio na região e os malefícios causados a população; criar grupos de discussão política sobre a questão agrária; buscar formas de articulação entre todos aqueles que militam no movimento de educação do campo; criar mecanismos para acompanhamento das políticas voltadas à educação do campo; criar mecanismos para monitorar as escolas rurais e impedir o seu fechamento; criação do Fórum Permanente de Educação do Campo da Região do Triângulo Mineiro; garantir assento nos Conselhos municipais de Educação para os militantes da educação do campo; realizar Jornadas de Educação do Campo nos Municípios, uma vez por ano; acionar os mecanismos jurídicos para garantir os direitos das escolas do campo (projeto Pedagógico próprio; contratação de professores, organização em alternância, calendário diferenciado etc.); garantir que todos os professores que atuam nas escolas do campo passem por um processo de capacitação em educação do campo para que possam ter uma atuação mais qualificada e de acordo com a realidade dos educandos; buscar estratégias para dinamizar a formação de professores nos cursos de Licenciatura de educação do campo.

Como visto, os desafios são grandes e precisamos estar unidos para superá-los, e essa não é uma opção, mas sim a única saída se quisermos continuar sonhando com a possibilidade de construirmos um novo paradigma para o território camponês e uma educação de qualidade para as novas gerações. 


\section{REFERÊNCIAS}

GHEDIN, E. (org.) Educação do campo: epistemologia e práticas. São Paulo: Cortez, 2012.

INEP. Sinopse Estatística da Educação Básica 2018. Brasília: Inep, 2019. Disponível em: http://portal.inep.gov.br/sinopse-estatistica-da-educacao-basica. Acesso em: 2 fev. 2019.

MACHADO, L. M.; OLIVEIRA, R. P. Direito à educação e legislação de ensino. In: WITTMANN, C.; GRACINDO, R. V. (org.). O estado da arte em política e gestão de educação no Brasil - 1991-1997. Brasília: ANPAE; Campinas: Autores Associados, 2001.

MARCUZZO, J. L.; RAMOS, M. P. A definiçãa de rural e urbano e o desenvolvimento regional: uma avaliação de diferentes metodologias de classificação. In: SEMINÁRIO INTERNACIONAL SOBRE DESENVOLVIMENTO REGIONAL, 2., 2004, Santa Cruz do Sul. Anais [...]. Disponível em: https://www.unisc.br/site/sidr/2004/urbano/01.pdf. Acesso em: 20 jan. 2020.

ORSO, P. J. Por uma educação para além do capital e por uma educação para além da escola. In: ORSO, J. P.; GONÇALVES, S. R.; MATTOS, V. M. (org.). Educação, Estado e contradições sociais. São Paulo: Outras Expressões, 2011. p. 225-246.

VEIGA, J. E. O Brasil rural ainda não encontrou seu eixo de desenvolvimento. Revista Estudos Avançados, Brasília, v. 15, n. 43, p. 101-119, set.-dez. 2001. Doi: 10.1590/S010340142001000300010. 